\title{
Sensory properties and drivers of liking for Greek yogurts
}

\author{
N. T. Desai, L. Shepard, and M. A. Drake ${ }^{1}$ \\ Department of Food, Bioprocessing and Nutrition Sciences, North Carolina State University, Raleigh 27695
}

\begin{abstract}
Greek yogurt is currently the largest growing sector in the dairy industry. Because no standard of identity exists for Greek yogurts in the United States, and they can be made by a variety of methods, variability in sensory properties is expected. Knowledge of consumer perception and specific drivers of liking will be useful information for product developers. The objective of this study was to document the sensory properties of commercial Greek yogurts and to determine drivers of liking through descriptive profiling and consumer testing. Flavor and texture attributes of commercial Greek yogurts $(\mathrm{n}=24)$ were evaluated in triplicate by a trained descriptive sensory panel. An online survey (n $=520$ ) was used to collect consumer usage and attitude information for Greek yogurts before consumer acceptance testing. Consumer acceptance testing $(\mathrm{n}=155)$ was then conducted on commercial Greek yogurts (n $=10$ ). Univariate and multivariate statistical analyses were used for data analysis. Sensory properties of yogurt differed with fat content and manufacture (Greek vs. fortified Greek). Full-fat yogurts were characterized by firmness and denseness, whereas low- and non-fat yogurts lacked firmness, denseness, cohesiveness, and, after stirring, viscosity. Fortified Greek yogurts generally had more surface shine and jiggle and lower denseness compared with traditional Greek yogurts. Fewer flavor differences were observed among yogurts compared with texture differences. Fortified Greek yogurts displayed a burnt/beefy flavor not documented in traditional Greek yogurts, but this flavor was not evident in all fortified Greek yogurts. Consumer preferred Greek yogurts with firm, dense texture, moderate sweet aromatic, milkfat and dairy sour flavors, and moderate sour taste. Consumers were aware of the increased protein content of Greek yogurts but generally unaware of differences between strained and fortified Greek yogurts; both strained Greek and fortified Greek yogurts received the highest overall liking scores in blinded acceptance testing. Successful Greek yogurts can be
\end{abstract}

Received April 29, 2013

Accepted August 6, 2013

${ }^{1}$ Corresponding author: mdrake@unity.ncsu.edu manufactured using addition of dried dairy ingredients or by traditional straining and centrifugation.

Key words: yogurt, Greek, flavor, sensory property

\section{INTRODUCTION}

Yogurt is a popular food and is believed to be one of the oldest fermented foods, originating in the Middle East and Asia (Tamime and Robinson, 1999). Yogurt production in 1980 was close to 260 million kilograms in the United States and increased to 2 billion kilograms in 2009. Yogurt dollar sales rose $7 \%$ to $\$ 5.2$ billion at the end of May 2011 (Ag MRC, 2013). The US Census Bureau 2012 survey revealed that per capita yogurt consumption has increased more than $400 \%$ during the past 30 yr (Dairy Foods Magazine, 2012). Increased yogurt consumption and production are attributed to the perceived health benefits of yogurt and its consumer appeal. The US Food and Drug Administration defines yogurt as, "the food produced by culturing one or more of the optional dairy ingredients cream, milk, partially skimmed milk or skimmed milk, used alone or in combination with a characterizing bacterial culture that contains the lactic acid producing bacteria, Lactobacillus bulgaricus and Streptococcus thermophilus (US Food and Drug Administration, 2008). Different types of yogurt are defined based on fat content. All yogurts, regardless of the fat content, must have a titratable acidity of at least $0.9 \%$ and $8.25 \%$ milk solids-not-fat.

Concentrated yogurt or Greek yogurt, known as strained yogurt in Europe, is a fermented semi-solid product derived from yogurt by draining away part of its water and water-soluble components. Strained yogurt is traditionally produced by straining yogurt in cloth bags until the desired level of total solids is achieved; however, modern manufacturing methods include the use of centrifugation and ultrafiltration (Nsabimana et al., 2005). Greek yogurt may also be manufactured using the addition of dried ingredients, including dairy protein ingredients or other hydrocolloids, to provide a thick texture; it is referred to as fortified or Greek-style yogurt when manufactured by using this approach. According to the Codex Standard for Fermented Milk (Codex Alimentarius, 2003), strained yogurt has to have increased protein content before or after fermentation 
to a minimum of $5.6 \%$ compared with regular yogurt, which has a protein content of minimum $2.7 \%$. No legal standard or definition exists in the United States for Greek or fortified Greek yogurt. The increased health awareness associated with the consumption of diets rich in protein has fueled the consumption of Greek yogurt (Jaoude et al., 2010). Greek yogurt accounted for about $25 \%$ of all segment sales, more than doubling the figures from the previous year (Anonymous, 2012a).

Sensory properties of yogurts have been documented. Muir and Hunter (1992) examined unflavored fermented milks, including yogurts, and concluded that 8 odor, 12 flavor, 4 aftertaste, and 8 texture attributes were important for the sensory description of these products. Barnes et al. (1991) and Harper et al. (1991) applied 14 attributes that differentiated and described these products. Martin et al. (1999) applied to a trained panel to document the effects of bacterial strain, temperature, $\mathrm{pH}$, and storage time on plain stirred yogurts. Brennan et al. (2002) used children to determine acceptance of yogurt thickness and its influence on perceived flavor intensity. More recently, Coggins et al. (2008) evaluated storage time and temperature effects on yogurt flavor and texture using descriptive analysis.

Preference mapping is used to establish relationships between descriptive panel results and consumer acceptance data (Meilgaard et al., 2007). Drivers of liking for many dairy products including drinkable strawberry yogurt (Thompson et al., 2007), Cheddar cheese (Drake and Yates, 2006; Drake et al., 2008, 2009a), and cottage cheese (Drake et al., 2009b) have been examined using preference mapping. Strawberry remains the most popular yogurt flavor, followed by other fruit flavors (Thompson et al., 2007). Allgeyer et al. (2010) concluded that for flavored yogurt drinks, a medium level of sweetness and a high viscosity drove consumer liking. Thompson et al. (2007) concluded that strawberry flavor, aroma, and sweetness were the 3 main drivers of liking for drinkable strawberry-flavored yogurts.

Sensory properties and drivers of liking for Greek or fortified Greek yogurt have not been reported. Because no standard of identity exists for Greek yogurts and they can be made by a variety of methods, variability in sensory properties is expected. The list of permissible ingredients is vast and the choice of ingredients used can affect sensory properties. Knowledge of consumer perception and specific drivers of liking will be useful information for product developers. The objective of this study was to document the sensory properties of commercial Greek yogurts and to determine drivers of liking through descriptive profiling and consumer testing. A category survey of commercial Greek yogurts was conducted followed by a consumer survey, acceptance testing, and preference mapping.

\section{MATERIALS AND METHODS}

\section{Yogurt}

Plain commercial Greek yogurts ( $\mathrm{n}=24,15$ strained, 9 fortified) were collected from across the United States. Yogurts were selected based on market share as well as fat content (full fat $=5$, reduced or low fat $=5$, and fat free $=14$ ). National, regional, and store brands were included. Samples were purchased from the store at least $30 \mathrm{~d}$ before their expiration date and stored in the dark at $4^{\circ} \mathrm{C}$. Each product was evaluated no later than $21 \mathrm{~d}$ before the expiration date. Triplicate lots of each brand were obtained approximately $20 \mathrm{~d}$ apart.

\section{Composition Analysis}

Proximate analysis was conducted on all the yogurts $(\mathrm{n}=24)$. They were analyzed for total solids by vacuum drying oven (AOAC International, 2012; method 990.20; 33.2.44). Measurement of $\mathrm{pH}$ was conducted using a Mettler-Toledo (Schewezenbach, Switzerland) probe (Combination Electrode, BNC, Corning, NY) at $4^{\circ} \mathrm{C}$. Protein content was determined using the Sprint Rapid Protein Analyzer (CEM, Matthews, NC), and fat content was determined by Mojonnier analysis. All measurements were taken in duplicate.

\section{Descriptive Analysis}

Sensory testing was conducted in compliance with the North Carolina State University (NCSU) Institutional Review Board for Human Subjects approval. Yogurts (30 g) were scooped into lidded 60-mL soufflé cups with random 3-digit codes. Yogurts were tempered to $12^{\circ} \mathrm{C}$ for tasting. Each sample was served monadically with deionized water and unsalted crackers.

A trained descriptive sensory panel $(n=8$, females, ages 24 to $50 \mathrm{yr}$ ) evaluated the samples using a 0-15 intensity scale consistent with the Spectrum method (Drake and Civille, 2003; Meilgaard et al., 2007). Each panelist had more than $200 \mathrm{~h}$ of prior experience with the descriptive analysis of flavor and texture of foods, and approximately $100 \mathrm{~h}$ of experience with descriptive analysis of dairy products, including cheese, sour cream, and milk powders. Yogurt attributes were generated in consensus across three 2-h sessions during which panelists tasted an array of yogurts along with other cultured dairy products (sour creams and buttermilks). The lexicon generated for yogurts included 10 flavor, 4 taste, 2 appearance, and 8 texture attributes (Tables 1 and 2). Ten 3 -h sessions were subsequently conducted to allow the panel to consistently identify and score the attributes. Analysis of variance of the data collected 
Table 1. Flavor attributes for Greek yogurts

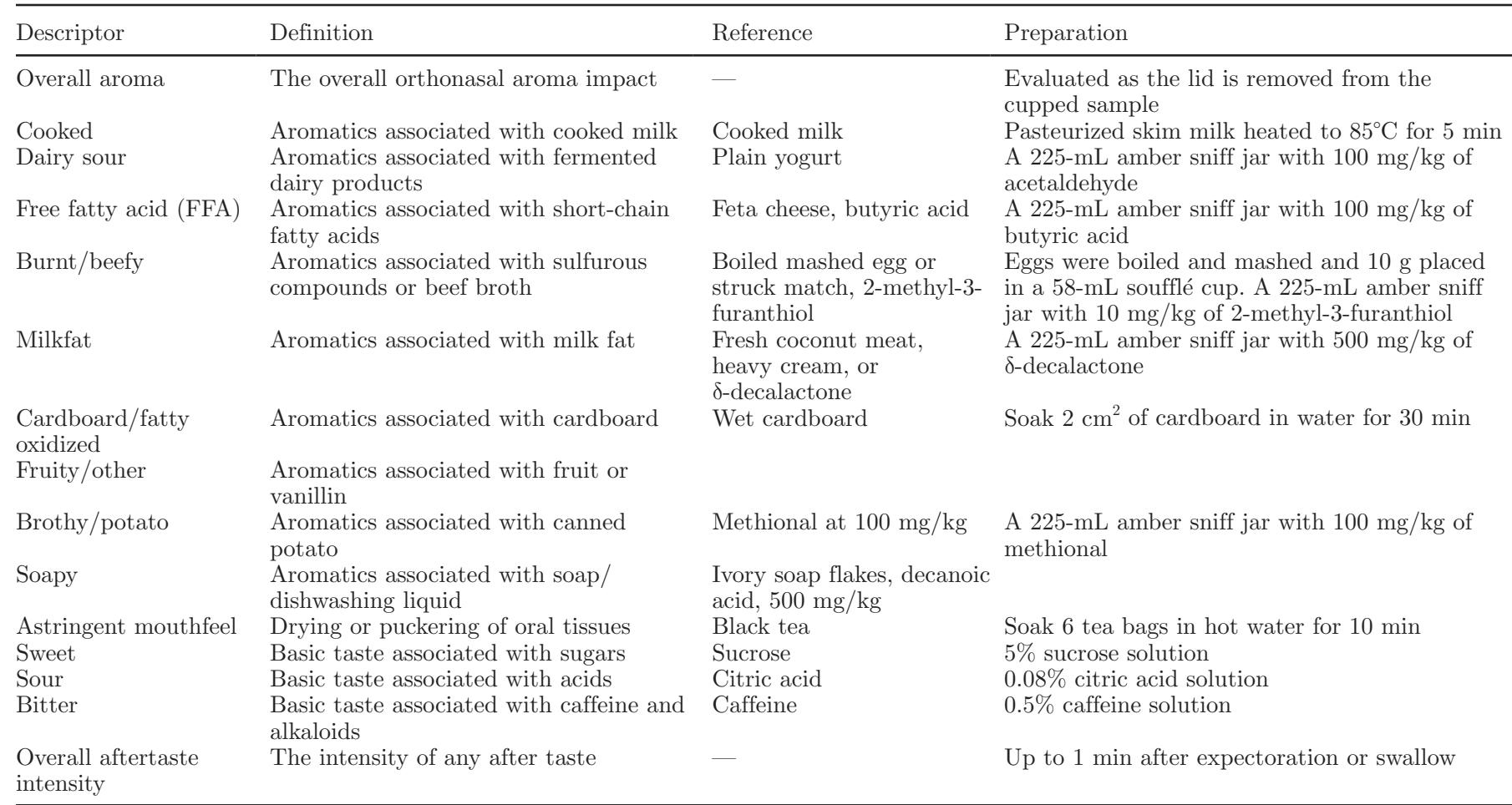

${ }^{1}$ Flavor attributes were scored using a 0 to 15 point universal intensity scale (Drake and Civille, 2003; Meilgaard et al., 2007). Most dairy product flavor attributes fall between 0 and 5 on this scale (Drake et al., 2008, 2009a; Wright et al., 2009). Terms were adapted from Drake et al. (2008, 2009a).

from the last part of training indicated that the panel and panelists could consistently use the attributes to differentiate the products. Each yogurt from each lot (24 samples from triplicate lots) was evaluated in duplicate by each panelist. Flavor, texture, and appearance attributes were evaluated in separate sessions. Compusense Five (version 4.8; Compusense, Guelph, ON, Canada) was used for data collection.

\section{Online Consumer Survey}

An online consumer survey $(\mathrm{n}=520)$ was conducted to determine how to best present yogurts for a consumer acceptance test and to gain further information on consumer knowledge of Greek yogurt. The survey was launched using SSI Web (version 7.0.22, Sawtooth Software, Orem, UT). The survey link was sent to a database of 4,300 consumers managed by the Sensory Service Center (NCSU, Raleigh, NC). Female consumers $>18$ yr of age who consumed Greek yogurt at least once within the last 3 mo were qualified to participate in the survey. Consumers were asked to indicate which stores they shopped at and flavors, brands, fat content, and size of yogurt container typically consumed and purchased. They were also asked how often they consumed Greek yogurt and how they typically used it. Participants were asked to rate the importance of Greek yogurt attributes and how well 1 serving size satisfied them compared with other food items. A drawing was conducted and 15 randomly selected participants who completed the survey were rewarded with a $\$ 20$ gift card.

\section{Consumer Acceptance Testing}

Commercial yogurts ( $\mathrm{n}=10 ; 5$ strained, 5 fortified; 1 full fat, 3 low fat, 6 nonfat) were selected for consumer acceptance testing based on examination of product mean attributes, principal component biplots and market share. Consumers were served the samples in the same manner as for descriptive analysis, except that samples were served at $4^{\circ} \mathrm{C}$. Consumer acceptance testing $(\mathrm{n}=155)$ took place over $2 \mathrm{~d}$. Greek yogurt consumers, women $(\mathrm{n}=155)$ with an equal age distribution (18 to $65 \mathrm{yr}$ ), were recruited from an online database maintained by the Sensory Service Center at NCSU. The database consisted of 4,300 individuals from the Raleigh, North Carolina, area recruited by magazine, newspaper, and online web advertisements. Self-reported Greek yogurt consumers were women who 
Table 2. Texture and visual attributes for Greek yogurts ${ }^{1}$

\begin{tabular}{|c|c|c|}
\hline Descriptor & Definition & Reference \\
\hline Surface grain & $\begin{array}{l}\text { The amount of particles that can be seen on the } \\
\text { surface of the product }\end{array}$ & $\begin{array}{l}\text { Jell-O pudding }=1 \text { and Philadelphia whipped cream cheese } \\
=12\end{array}$ \\
\hline Spoon ropy & $\begin{array}{l}\text { Visible threading off the spoon as the product is } \\
\text { spooned }\end{array}$ & Brown Cow plain yogurt $=4$ \\
\hline Surface grain on spoon & $\begin{array}{l}\text { The amount of particles that can be seen on the } \\
\text { surface of the product }\end{array}$ & Jell-O pudding $=1.5$ and Skippy peanut butter $=9$ \\
\hline Firmness & $\begin{array}{l}\text { Force required to compress the product between } \\
\text { tongue and palate }\end{array}$ & Jell-O pudding $=3$ and Jell-O gelatin $=10$ \\
\hline Denseness & $\begin{array}{l}\text { Compactness of the cross section, absence of air } \\
\text { perceived as the tongue is moved through the sample }\end{array}$ & $\begin{array}{l}\text { Kraft marshmallow fluff }=2.8 \text {, whipped cream cheese }=5 \text {, } \\
\text { Jell-O pudding }=9 \text {, and Philadelphia cream cheese }=13\end{array}$ \\
\hline Viscosity & Force required to move the spoon back and forth & Water $=1$ and Jell-O pudding $=10$ \\
\hline $\begin{array}{l}\text { Viscosity slurping off } \\
\text { spoon }\end{array}$ & $\begin{array}{l}\text { Force required to slurp the sample off the spoon from } \\
\text { in front of lips }\end{array}$ & $\begin{array}{l}\text { Water }=1 \text {, Hershey's chocolate syrup }=6 \text { and Jell-O } \\
\text { pudding }=12\end{array}$ \\
\hline Mouthcoating & $\begin{array}{l}\text { Degree to which any sample residue remains on the } \\
\text { mouth surface after swallowing }\end{array}$ & $\begin{array}{l}\text { Whole milk }=4 \text {, Jell-O pudding }=9 \text { and peanut butter }= \\
15\end{array}$ \\
\hline
\end{tabular}

${ }^{1}$ Texture attributes were scored using a 0 to 15 point product-specific scale (Drake and Civille, 2003; Meilgaard et al., 2007). Terms were adapted from Foegeding and Drake (2007) and Drake and Yates (2006).

consumed Greek yogurt at least once a month. All consumers were the primary shoppers in their households and purchased, as well as consumed, yogurt. Consumers who participated were compensated with $\$ 15$ Target gift card.

For each session, participants signed a consent form for human subject approval followed by a ballot consisting of questions about yogurt. Products were then evaluated. Each sample was scooped as the participant arrived. Yogurts $(50 \mathrm{~g})$ were served in soufflé cups (118 $\mathrm{mL}$ ) with a 3-digit code. Data were collected using Compusense Five or paper ballots (Plemmons and Resurreccion, 1999; Swaney-Stueve and Heymann, 2002). Along with each yogurt, strawberry fruit prep (Fruit Crown Products Corp., Farmingdale, NY) was served (18 g) in a $29-\mathrm{mL}$ soufflé cup. The participants were instructed to consume the fruit prep with the yogurt if they desired and however they wanted.

Participants were first asked to evaluate the overall appearance and color of the sample. The appearance of each sample was scaled using a 1-9 hedonic scale, where $1=$ dislike extremely and $9=$ like extremely. They were then asked to taste the sample and evaluate their overall impression using a 9-point hedonic scale. Consumers were then asked to evaluate flavor, sour taste, texture, thickness, and smoothness liking using a 9-point hedonic scale. This was followed by just-about-right (JAR) questions for sour taste, texture, creaminess, and smoothness, where 1 and $2=$ not enough, $3=$ just about right, and 4 and $5=$ too much. Consumers were then asked how likely they would be to purchase this product. A 5-point scale was used to answer this question, where 1 and $2=$ definitely would not buy, 3 = may or may not buy, and 4 and $5=$ definitely would buy.

Twelve consumers were randomly selected for a brief interview after their consumer test. A questionnaire was prepared to further probe their preferences and awareness of Greek yogurt (Table 3). The interviews were carried out in a conference room on an individual basis and lasted approximately $20 \mathrm{~min}$. The chosen consumers were compensated with an additional $\$ 5$ Target gift card.

\section{Statistical Analysis}

All statistical analysis was conducted with XLSTAT (version 2010.3.09; Addinsoft, New York, NY). Descriptive analysis and liking scores were evaluated by ANOVA with Fisher's least significant difference (LSD) post hoc test. Just-about-right scores were evaluated using chi-squared analysis. Purchase intent was evaluated using Kruskal-Wallis with Dunn's post hoc test. All statistics were calculated to the $95 \%$ confidence level. Consumer cluster analysis was conducted using $\mathrm{k}$ means. Clusters were validated using discriminant analysis. To produce the external preference map, a 
Table 3. Questions asked of consumers during in-depth interview

Question

1. Do you consume more of regular yogurt or Greek yogurt?

2. Do you generally prefer plain yogurt or flavored?

3. Which factor primarily influences your yogurt purchase?

4. Which brand do you commonly purchase?

5. Why do you consume Greek yogurt?

6. Is it more satisfying than regular yogurt (if yes, why)?

7. Do you think Greek yogurt is made differently or has different ingredients than regular yogurt?

principal component map was first generated from the descriptive panel profiles, and overall acceptance ratings of the consumers were regressed onto the plot using partial least squares (PLS) regression.

\section{RESULTS AND DISCUSSION}

\section{Composition}

Proximate analyses of Greek yogurts was variable $(P$ $<0.05$ ) but consistent with labels (results not shown). Fat content ranged from 0.05 to $4.9 \%$ (wet weight). Protein and total solids ranged from 5.8 to $10.6 \%$ (wet weight) and from 15 to $23.8 \%$, respectively. Percent lactic acid and $\mathrm{pH}$ ranged from 3.3 to $5.4 \%$ and from 4.4 to 4.9 , respectively. Total solids, $\mathrm{pH}$, and lactic acid content did not differ $(P>0.05)$ between strained and fortified Greek yogurts, whereas protein content differed (9.2 vs. $7.7 \%$ protein, respectively; $P<0.05$ ). Fortified Greek yogurts may be manufactured by the addition of dried protein ingredients as well as hydrocolloids, which may explain the lower overall protein content of fortified Greek yogurts compared with strained Greek yogurts.

\section{Descriptive Analysis}

Thirty-two sensory attributes were identified and defined for Greek yogurts. The sensory lexicon developed included 4 visual, 10 aromatic, 3 basic taste, 2 chemical feeling, and 10 textural attributes (Tables 1 and 2). All yogurts had the following attributes: overall aroma intensity, cooked, dairy sour, astringent, sweet, sour, and overall aftertaste intensity. Trained panelists documented differences $(P<0.05)$ with all attributes, confirming the utility of the lexicon (and the panel) to document differences among the samples (Drake and Civille, 2003).

Principal component (PC) analysis of the flavor data explained $65 \%$ of the variability on $3 \mathrm{PC}$ (Figure 1). Principal component $1(26 \%)$ comprised overall aroma, cooked/milky, burnt/beefy, cardboard, and aftertaste, whereas PC $2(23 \%)$ comprised milkfat, soapy, astringency, and sweet and sour tastes (Figure 1) and PC
$3(16 \%)$ comprised FFA and fruity/other (Figure 2). Fortified Greek yogurts were generally characterized by cooked, burnt/beefy, brothy/potato, and dairy sour flavors, and astringency (Figures 1 and 2). Traditional Greek strained yogurts were characterized by FFA, cardboard, and soapy flavors and sweet taste (Figures 1 and 2).

Full-fat Greek yogurts 517, 126, 266, 248, and 145, had the highest intensities of milkfat flavor followed by reduced-fat yogurts 590, 815, 250 and 357 (results not shown). Yogurts 222 and 112 had the lowest intensity of dairy sour flavor, possibly because the added food starch and pectin reduced the concentration of aroma compounds in the headspace (Decourcelle et al., 2004). Fortified Greek yogurts 729,145, 357 and 015, which contained added whey protein concentrate or milk protein concentrate, exhibited burnt/beefy flavor. White et al. (2013) recently demonstrated that heat treatment of whey proteins in model beverages at neutral or acidic conditions resulted in release or formation of sulfur and brothy flavors. It is likely that heat treatment of the yogurt mix with added protein contributed to formation of protein-derived compounds that impart the burnt/ beefy flavor. Fruity flavor was detected in 2 yogurts (222 and 694). One of these (222) was vanilla flavored and the other (694) was a plain non-fat fortified Greek yogurt. Brothy/potato, soapy, and cardboard flavors were not detected in all yogurts but were present in both fortified and strained Greek yogurts. These flavors may be due to processing conditions or ingredients. All 3 flavors have been previously documented in dried whey and milk ingredients (Drake and Civille, 2003; Wright et al., 2009) but may also be caused by heat treatment or lipid oxidation of fluid (milk) components (Whitson et al., 2010; White et al., 2013).

Sour taste was the predominant sensory attribute in yogurts, ranging from 2.5 to 11.2 on the 15-point Spectrum universal scale, which is characteristic of fermented dairy products. Sample 357, a fortified yogurt, had the highest intensity of sour taste and dairy sour flavor, 11.2 and 4.2, respectively. Full-fat sample 517 was higher in milkfat flavor compared with other yogurts and also had a higher fat content than the other yogurts. Burnt/beefy flavor was not detected in Greek 
Biplot (axes PC1 and PC2: $49 \%$ )

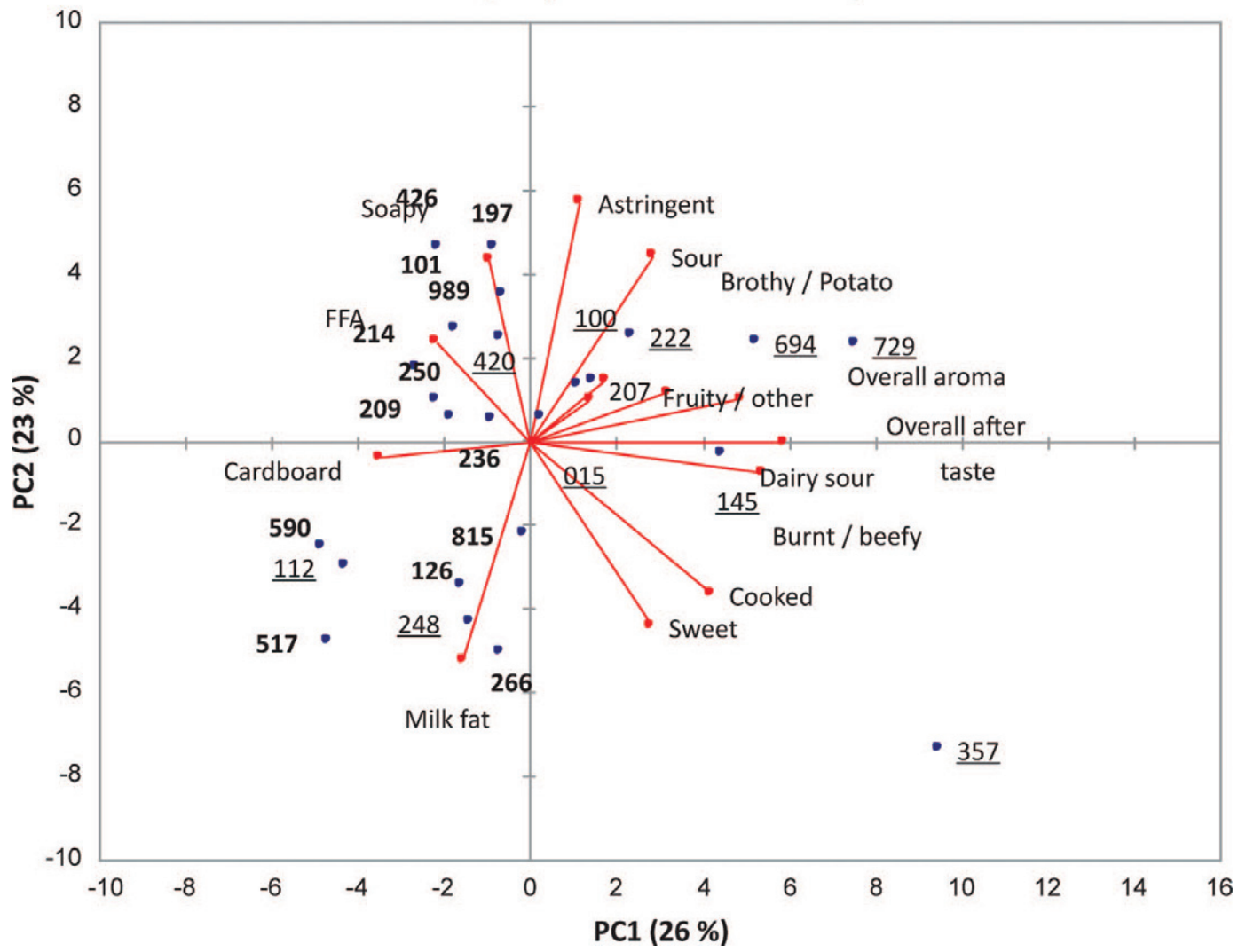

Figure 1. Principal component (PC) analysis biplot of flavor attributes of yogurts. Traditional Greek strained yogurts are indicated by bold numbers; fortified Greek yogurts are indicated by underlined numbers. Yogurts 590, 357, 112, 815, and 250 were $2 \%$ milkfat yogurts; 517,126 , 145, 248, and 266 were whole-milk yogurts; all other yogurts were fat free. Color version available in the online PDF.

strained yogurts. Yogurts 112 and 222 were the only fortified Greek yogurts that did not have detectable burnt/beefy flavor; these contained only pectin and no dried dairy ingredients, suggesting dairy protein ingredients as the source of this flavor in fortified Greek yogurts.

Principal component analysis of texture and visual appearance explained $64 \%$ of the variability among yogurts (Figure 3). Principal component 1 (46\%) comprised firmness before stirring, firmness after stirring, denseness before and after stirring, viscosity, slurp viscosity, cohesiveness, meltaway, and mouthcoating (Figure 3). Principal component $2(18 \%)$ comprised surface shine, surface grain, spoon indent, jiggle, and graininess. Strained Greek yogurts were generally characterized by denseness before and after stirring, firmness before and after stirring, cohesiveness, and viscosity (Figure 3).

Fortified Greek yogurts were generally characterized by surface shine, jiggle, and meltaway. Samples 729 and 222 had the highest intensity of surface shine (14.0 for both). Yogurt 207 had the highest intensity of surface grain on the spoon and surface grain, 10.9 and 9.0, re- spectively. Full-fat strained yogurt 517 had the highest intensity of viscosity, slurp viscosity, and cohesiveness, and the lowest intensity of meltaway $(13.1,14.6,7.3$, and 6.1 , respectively). Fortified yogurts 112 and 145 were ropy (2.8 and 1.0, respectively). Ropy was not observed in any of the Greek strained yogurts. Processing conditions, starter culture, and ingredients used can all significantly affect the texture of yogurts (Ayub, 2004; Sodini and Tong, 2006).

\section{Consumer Survey}

Ninety-five percent of the consumers surveyed $(\mathrm{n}=$ 492) consumed Greek yogurt at least once a month. Most consumers (54\%) consumed low-fat yogurts, $26 \%$ consumed non-fat yogurts, and $20 \%$ consumed full-fat yogurts (Table 4). Eighty-one percent of consumers preferred to purchase single-serving sizes of yogurt compared with $19 \%$ who purchased 8- or 16-oz. tubs (Table 4). Greek yogurt was primarily used as a snack (79.5\%); a smaller number of consumers used Greek yogurt as part of a meal (48.5\%) or as a meal (31.5\%). 


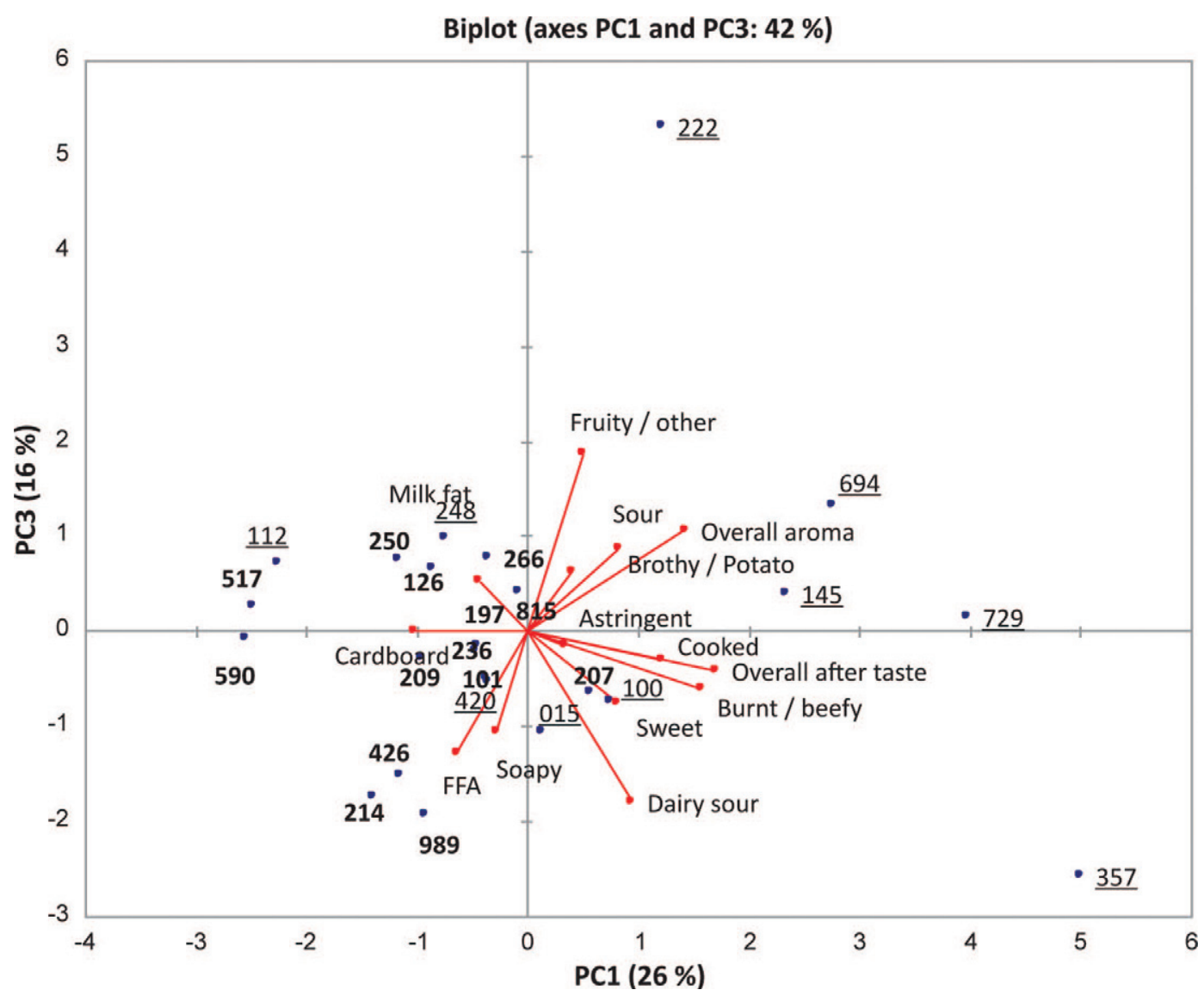

Figure 2. Principal component (PC) analysis biplot of flavor attributes of yogurts. Traditional Greek strained yogurts are indicated by bold numbers; fortified Greek yogurts are indicated by underlined numbers. Yogurts 590, 357, 112, 815, and 250 were $2 \%$ milkfat yogurts; 517, 126, 145,248 , and 266 were whole-milk yogurts; all other yogurts were fat free. Color version available in the online PDF.

Brand usage was consistent with reported market share. Fifty-seven percent of the consumers knew that they consumed strained Greek yogurt, whereas $12 \%$ said they consumed fortified Greek or Greek style, and the remaining $31 \%$ did not know whether they consumed strained Greek or Greek style. Strawberry flavor was rated as the most consumed yogurt flavor, which was consistent with previous studies (Thompson et al., 2007).

\section{Consumer Acceptance Testing}

Greek yogurt consumer purchase and consumption habits were consistent with results from the online survey (results not shown). Consumers were asked to rank the importance of factors that influenced their purchase of Greek yogurt. Flavor was the top factor followed by price, brand, availability, and coupons.

Yogurt 517, a full-fat strained yogurt, received the highest overall impression score along with the highest flavor and texture liking scores (Table 5). Yogurts
420, 694, 112, and 815 (non-fat and low-fat yogurts, strained and fortified) were the next best liked yogurts with no differences in liking among them (Table 5). Given that yogurt 517 was the only full-fat yogurt evaluated and that both strained and fortified low-fat and non-fat Greek yogurts received the next highest liking scores with no differences among these 4 yogurts, these results suggest that milkfat was the key attribute for the high overall liking score of yogurt 517. Most consumers reported that they chose to purchase and consume reduced, low-, or non-fat yogurt (Table 4), but when yogurts were presented blinded, a full-fat yogurt was preferred across all consumers. Yogurts 517 and 112 were the only samples to receive $50 \%$ or more for all categories of JAR questions (Table 5). Yogurts 015 and 357 received the lowest liking scores and had added whey protein concentrate and milk protein concentrate. The collected data from the interviews suggested that consumers preferred flavored Greek yogurt (11/12 consumers interviewed), enjoyed the thick texture (12/12), and thought that it was more satisfying than regular 
Biplot (axes PC1 and PC2: 64 \%)

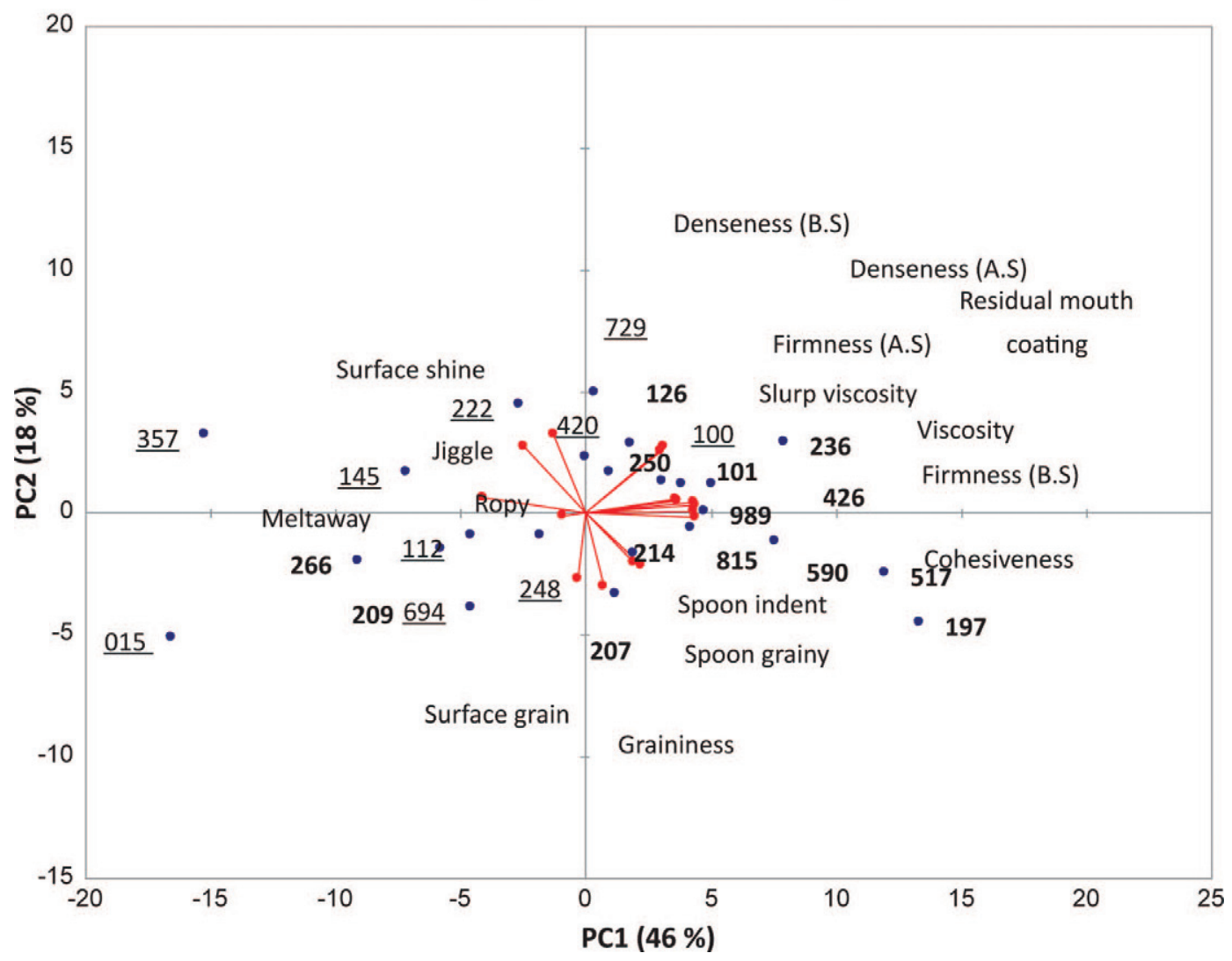

Figure 3. Principal component (PC) analysis biplot of textural and visual appearance attributes of yogurts. B.S. = before stir, A.S. = after stir. Traditional Greek strained yogurts are indicated by bold numbers; fortified Greek yogurts are indicated by underlined numbers. Yogurts $590,357,112,815$, and 250 were $2 \%$ milkfat yogurts; $517,126,145,248$, and 266 were whole-milk yogurts; all other yogurts were fat free. Color version available in the online PDF.

yogurt (12/12). Consumers polled in interviews had no idea if Greek yogurt was made differently or had different ingredients than regular yogurt, but they knew that it contained a higher protein content and had a thicker texture and as such, thought that something was different.

Consumer segmentation was used to investigate specific consumer preferences and drivers of liking for Greek yogurts. Three clusters were identified (Table 6). Cluster $1(\mathbf{C} 1 ; \mathrm{n}=40)$ comprised consumers that liked a moderately firm texture, higher meltaway and mouthcoating, and higher sweet taste and overall aroma intensity. Sour taste, dairy sour, cooked, and burnt/beefy flavors were drivers of dislike for $\mathrm{C} 1$ consumers. Cluster $2($ C2 $)$ consumers $(\mathrm{n}=45)$ liked dense, firm, and cohesive texture along with milkfat flavor and sweet taste. Cluster 3 (C3) consumers $(\mathrm{n}=70)$ liked Greek yogurts with high sour taste, milkfat and dairy sour flavors, viscosity, and low surface grain, whereas they disliked sweet taste. For all 3 clusters, the top scoring yogurts were an equal distribution among Greek strained yo- gurts and fortified Greek yogurts, which suggests that consumer preferences for traditional strained yogurts versus yogurts with added ingredients were not apparent. This also leads to the conclusion that as long as atypical flavors were not present, the manufacturing process did not influence consumer liking.

Cluster analyses were confirmed by assessing product attributes and liking of each product by clusters. Sample main effects and sample $\times$ cluster interactions $(F=23.60, P<0.05)$ were observed. The sample $\times$ cluster interaction suggests that clusters liked samples differently and further confirms the clusters. Sample 517 was highly ranked among $\mathrm{C} 2$ and $\mathrm{C} 3$ and was not ranked as high by $\mathrm{C} 1$ (Table $6 ; P<0.05$ ). Sample 517 was characterized by sweet taste, cohesiveness, firmness, denseness, and viscosity. Samples 112, 236, 357, 694, and 989 received higher liking scores from $\mathrm{C} 2$ consumers than from $\mathrm{C} 1$ and $\mathrm{C} 3$ consumers. The higher scores for these yogurts were likely caused by the combination of sweet taste, denseness, cohesiveness, and lack of FFA. The lower scores from consum- 
Table 4. Information obtained from online consumer survey

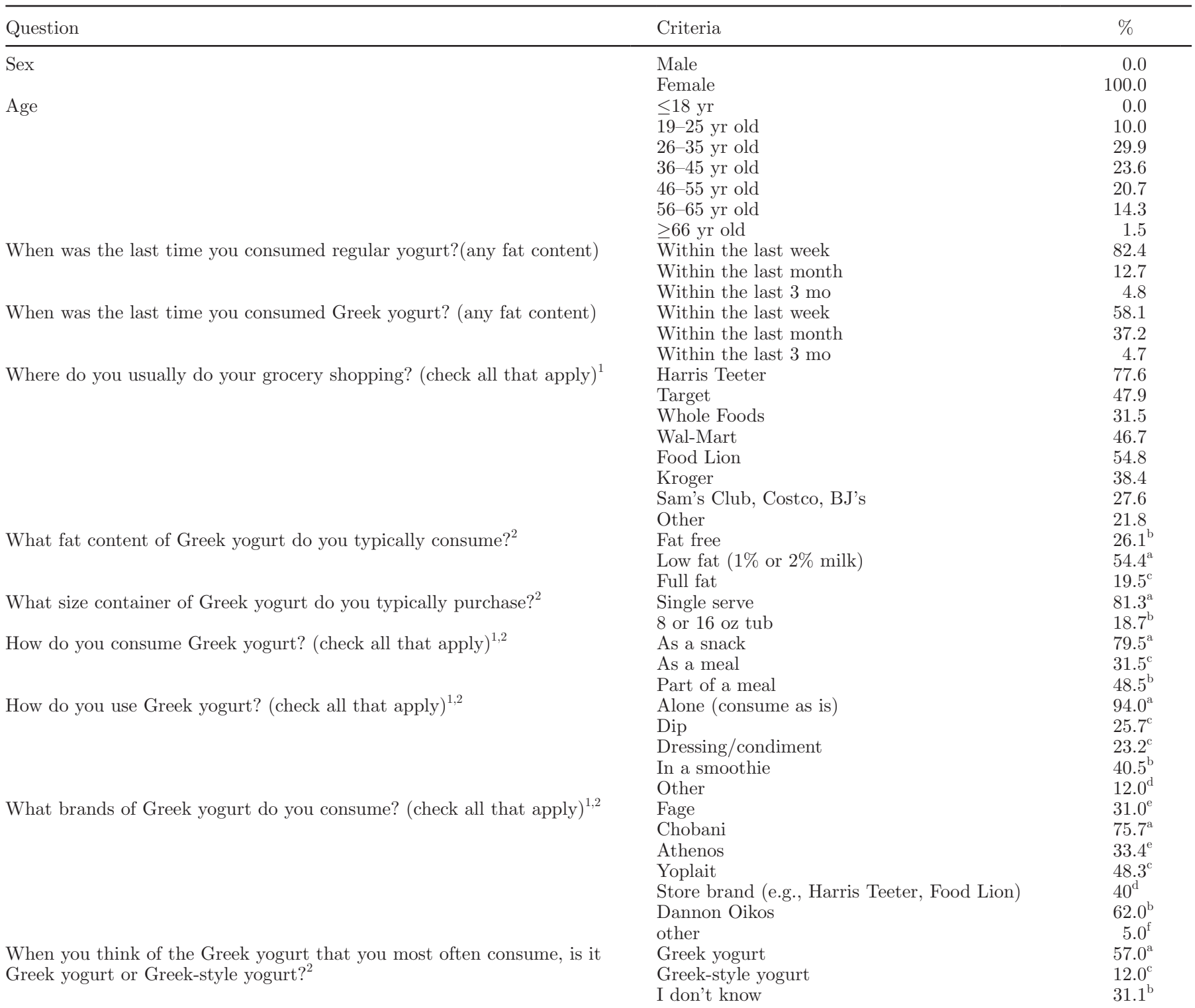

What flavors of Greek yogurts do you typically consume? ${ }^{2}$

\begin{tabular}{ccc} 
Rank 1 & Rank 2 & Rank 3 \\
\hline $33.6^{\mathrm{a}}$ & $26.3^{\mathrm{a}}$ & $16.6^{\mathrm{b}}$ \\
$15.6^{\mathrm{c}}$ & $22.0^{\mathrm{ab}}$ & $25.3^{\mathrm{a}}$ \\
$9.1^{\mathrm{d}}$ & $19.7^{\mathrm{bc}}$ & $21.6^{\mathrm{a}}$ \\
$12.5^{\mathrm{cd}}$ & $15.6^{\mathrm{c}}$ & $12.0^{\mathrm{cd}}$ \\
$20.1^{\mathrm{b}}$ & $7.9^{\mathrm{d}}$ & $15.6^{\mathrm{bc}}$ \\
$9.1^{\mathrm{d}}$ & $8.5^{\mathrm{d}}$ & $8.9^{\mathrm{d}}$ \\
\hline
\end{tabular}

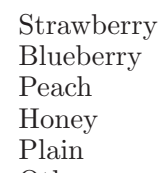

${ }^{1}$ Total percentage exceeds $100 \%$ as consumers were able to select multiple response; data represent 518 consumers.

${ }^{2}$ Statistical lettering was obtained from $\chi^{2}$ analysis using k proportions. Different superscript letters in rows following means signify significant differences $(P<0.05)$.

ers in C3 for sample 015 might have been due to the combination of overpowering sweet taste, low sour taste, low viscosity, and cohesiveness (Table 6). Sample 517 was relatively liked by all clusters, which might be due to this product having a moderate amount of sweet and sour taste, high milk fat flavor, as well as high firm and dense texture (Table 6). Sample 357 was liked by $\mathrm{C} 2$ consumers and not liked as much by $\mathrm{C} 1$ and $\mathrm{C} 3$ consumers (Table 6 ). Sample 357 was characterized by brothy/potato, cooked and burnt/ 
Table 5. Overall liking attribute means from consumer acceptance testing of Greek yogurt ${ }^{1}$

\begin{tabular}{|c|c|c|c|c|c|c|c|c|c|c|}
\hline Item & \multicolumn{10}{|c|}{ Greek yogurt type ${ }^{2}$} \\
\hline Appearance liking & $4.6^{\mathrm{f}}$ & $6.1^{\mathrm{e}}$ & $6.8^{\mathrm{ab}}$ & $6.7^{\mathrm{bc}}$ & $6.6^{\mathrm{bc}}$ & $6.2^{\mathrm{de}}$ & $7.1^{\mathrm{a}}$ & $7.0^{\mathrm{ab}}$ & $6.4^{\mathrm{cd}}$ & $6.4^{\text {cde }}$ \\
\hline Overall impression & $3.8^{\mathrm{e}}$ & $6.0^{\mathrm{b}}$ & $5.5^{\mathrm{c}}$ & $3.9^{\mathrm{e}}$ & $6.1^{\mathrm{b}}$ & $6.8^{\mathrm{a}}$ & $6.0^{\mathrm{b}}$ & $5.0^{\mathrm{d}}$ & $6.1^{\mathrm{b}}$ & $5.9^{\mathrm{b}}$ \\
\hline Flavor liking & $4.5^{\mathrm{d}}$ & $6.1^{\mathrm{b}}$ & $5.3^{\mathrm{c}}$ & $3.6^{\mathrm{e}}$ & $5.6^{\mathrm{bc}}$ & $6.8^{\mathrm{a}}$ & $5.7^{\mathrm{bc}}$ & $4.4^{\mathrm{d}}$ & $5.9^{\mathrm{b}}$ & $5.6^{\mathrm{bc}}$ \\
\hline Sour taste liking & $4.4^{\mathrm{cd}}$ & $5.9^{\mathrm{a}}$ & $4.8^{\mathrm{bc}}$ & $2.9^{\mathrm{e}}$ & $5.0^{\mathrm{b}}$ & $6.2^{\mathrm{a}}$ & $5.1^{\mathrm{b}}$ & $4.0^{\mathrm{d}}$ & $5.2^{\mathrm{b}}$ & $5.2^{\mathrm{b}}$ \\
\hline \multicolumn{11}{|l|}{ Sour taste $(\%)$} \\
\hline Too weak & $22.58^{\mathrm{a}}$ & $22.58^{\mathrm{a}}$ & $8.39^{\mathrm{bc}}$ & $0.00^{\mathrm{e}}$ & $5.81^{\mathrm{cd}}$ & $15.48^{\mathrm{ab}}$ & $9.68^{\mathrm{bc}}$ & $17.42^{\mathrm{a}}$ & $1.94^{\mathrm{de}}$ & $14.84^{\mathrm{ab}}$ \\
\hline JAR & $38.06^{\mathrm{c}}$ & $56.77^{\mathrm{ab}}$ & $41.94^{\mathrm{c}}$ & $10.97^{\mathrm{e}}$ & $39.35^{\mathrm{c}}$ & $60.65^{\mathrm{a}}$ & $45.81^{\mathrm{bc}}$ & $22.58^{\mathrm{d}}$ & $47.10^{\mathrm{bc}}$ & $39.35^{\mathrm{c}}$ \\
\hline Too strong & $39.35^{\mathrm{d}}$ & $20.65^{\mathrm{e}}$ & $49.68^{\mathrm{bc}}$ & $89.03^{\mathrm{a}}$ & $54.84^{\mathrm{bc}}$ & $23.87^{\mathrm{e}}$ & $44.52^{\mathrm{cd}}$ & $60.00^{\mathrm{b}}$ & $50.97^{\mathrm{bc}}$ & $45.81^{\mathrm{cd}}$ \\
\hline \multicolumn{11}{|l|}{ Texture (\%) } \\
\hline Too thin & $32.36^{\mathrm{a}}$ & $13.55^{\mathrm{bc}}$ & $12.90^{\mathrm{bc}}$ & $37.42^{\mathrm{a}}$ & $9.68^{\mathrm{bcd}}$ & $0.65^{\mathrm{e}}$ & $7.10^{\mathrm{cd}}$ & $16.77^{\mathrm{b}}$ & $4.52^{\mathrm{d}}$ & $27.10^{\mathrm{a}}$ \\
\hline Too creamy & $5.16^{\mathrm{a}}$ & $5.16^{\mathrm{a}}$ & $4.52^{\mathrm{a}}$ & $9.68^{\mathrm{a}}$ & $8.39^{\mathrm{a}}$ & $7.74^{\mathrm{a}}$ & $4.52^{\mathrm{a}}$ & $8.39^{\mathrm{a}}$ & $4.52^{\mathrm{a}}$ & $7.10^{\mathrm{a}}$ \\
\hline \multicolumn{11}{|l|}{ Smoothness (\%) } \\
\hline Not smooth & $81.29^{\mathrm{a}}$ & $32.90^{\mathrm{b}}$ & $25.16^{\mathrm{bc}}$ & $15.48^{\mathrm{d}}$ & $23.23^{\mathrm{bc}}$ & $18.06^{\mathrm{cd}}$ & $25.81^{\mathrm{bc}}$ & $12.90^{\mathrm{d}}$ & $20.00^{\mathrm{cd}}$ & $20.65^{\mathrm{cd}}$ \\
\hline JAR & $16.77^{\mathrm{d}}$ & $61.94^{\mathrm{c}}$ & $72.90^{\mathrm{ab}}$ & $70.32^{\mathrm{bc}}$ & $70.97^{\mathrm{bc}}$ & $77.42^{\mathrm{ab}}$ & $69.03^{\mathrm{bc}}$ & $80.65^{\mathrm{a}}$ & $77.42^{\mathrm{ab}}$ & $70.97^{\mathrm{bc}}$ \\
\hline Too smooth & $1.94^{\mathrm{d}}$ & $5.16^{\text {bcd }}$ & $1.94^{\mathrm{d}}$ & $14.19^{\mathrm{a}}$ & $5.81^{\mathrm{bcd}}$ & $4.52^{\mathrm{bcd}}$ & $5.16^{\text {bcd }}$ & $6.45^{\mathrm{bc}}$ & $2.58^{\mathrm{cd}}$ & $8.39^{\mathrm{ab}}$ \\
\hline Purchase intent ${ }^{3}$ & $1.8^{\mathrm{e}}$ & $3.0^{\mathrm{bc}}$ & $2.9^{\mathrm{c}}$ & $1.9^{\mathrm{e}}$ & $2.9^{\mathrm{bc}}$ & $3.7^{\mathrm{a}}$ & $3.0^{\mathrm{bc}}$ & $2.5^{\mathrm{d}}$ & $3.2^{\mathrm{b}}$ & $3.0^{\mathrm{bc}}$ \\
\hline
\end{tabular}

${ }^{\mathrm{a} f}$ Different superscript letters in rows following means signify significant differences $(P<0.05)$.

${ }^{1}$ Data represent 155 consumers. Liking attributes were scored on a 9-point hedonic scale, where dislike extremely $=1$ and like extremely $=9$. Just-about-right (JAR) scales were scored on a 5 -point scale where too little $=1$ or 2 , just about right $=3$, and too much $=4$ or 5 ; results indicate the percentage of consumers that selected these options.

${ }^{2}$ Yogurts 015, 112, 517, 694, 815, and 989 were Greek strained yogurts; 236, 357, 420, and 729 were fortified Greek yogurts; 015, 236, 420, 694, 729 , and 989 were fat-free yogurts; 112,357 , and 815 were $2 \%$ milkfat yogurts; and 517 was a full-fat yogurt.

${ }^{3}$ Purchase intent was scored on a 5 -point scale where would not buy $=1$ or 2 , maybe/maybe not $=3$, and would buy $=4$ or 5 ; statistical analysis (superscript letters) were obtained from Kruskal-Wallis nonparametric test.

beefy flavors, and lower firmness compared with other yogurts (Figures 1 to 3). Samples 517, 815, and 420 were liked by $\mathrm{C} 3$ consumers, probably because of sour taste, milkfat flavor, and viscosity intensities (Figures 1 to 3 ; Table 6 ).
Partial least squares regression was conducted to determine the drivers of liking for each consumer cluster (Figure 4). Drivers of liking were identified using the variable importance projection scores. For $\mathrm{C} 1$ consumers, the drivers of liking were moderate sweet taste,

Table 6. Overall liking means for each consumer cluster $^{1}$

\begin{tabular}{lccc}
\hline Sample $^{2}$ & $\begin{array}{c}\text { Cluster } 1 \\
(\mathrm{n}=40)\end{array}$ & $\begin{array}{c}\text { Cluster } 2 \\
(\mathrm{n}=45)\end{array}$ & $\begin{array}{c}\text { Cluster 3 } \\
(\mathrm{n}=70)\end{array}$ \\
\hline 015 & $4.68^{\mathrm{C}, \mathrm{a}}$ & $4.38^{\mathrm{D}, \mathrm{a}}$ & $2.80^{\mathrm{D}, \mathrm{b}}$ \\
112 & $6.23^{\mathrm{A}, \mathrm{b}}$ & $7.36^{\mathrm{A}, \mathrm{a}}$ & $5.03^{\mathrm{C}, \mathrm{c}}$ \\
236 & $4.85^{\mathrm{C}, \mathrm{c}}$ & $6.18^{\mathrm{BC}, \mathrm{a}}$ & $5.36^{\mathrm{BC}, \mathrm{b}}$ \\
357 & $2.27^{\mathrm{D}, \mathrm{c}}$ & $6.58^{\mathrm{AB}, \mathrm{a}}$ & $3.13^{\mathrm{D}, \mathrm{b}}$ \\
420 & $5.28^{\mathrm{BC}, \mathrm{b}}$ & $5.78^{\mathrm{C}, \mathrm{b}}$ & $6.73^{\mathrm{A}, \mathrm{a}}$ \\
517 & $5.90^{\mathrm{AB}, \mathrm{b}}$ & $6.82^{\mathrm{AB}, \mathrm{a}}$ & $7.33^{\mathrm{A}, \mathrm{a}}$ \\
694 & $5.88^{\mathrm{AB}, \mathrm{b}}$ & $6.60^{\mathrm{AB}, \mathrm{a}}$ & $4.81^{\mathrm{B}, \mathrm{b}}$ \\
729 & $6.05^{\mathrm{AB}, \mathrm{a}}$ & $4.27^{\mathrm{D}, \mathrm{b}}$ & $6.99^{\mathrm{A}, \mathrm{a}}$ \\
815 & $4.50^{\mathrm{C}, \mathrm{c}}$ & $6.22^{\mathrm{BC}, \mathrm{b}}$ & $5.91^{\mathrm{B}, \mathrm{b}}$ \\
\hline 89 & $5.80^{\mathrm{AB}, \mathrm{b}}$ & $6.20^{\mathrm{BC}, \mathrm{a}}$ & \\
\hline
\end{tabular}

${ }^{\mathrm{A}-\mathrm{D}}$ Means in a column with different uppercase letters are statistically different $(P<0.05)$.

${ }^{\mathrm{a}-\mathrm{c}}$ Means in a row with different lowercase letters are statistically different $(P<0.05)$.

${ }^{1}$ Liking attributes were scored on a 9-point hedonic scale, where dislike extremely $=1$ and like extremely $=9$.

${ }^{2}$ Yogurts $015,112,517,694,815$, and 989 were Greek strained yogurts; 236, 357, 420, and 729 were fortified Greek yogurts; $015,236,420,694,729$, and 989 were fat-free yogurts; 112,357 , and 815 were $2 \%$ milkfat yogurts; and 517 was a full-fat yogurt. 
overall aroma intensity, meltaway, mouthcoating, overall aftertaste intensity, and firmness. Cluster 1 consumers scored yogurts 729 and 989 as their top choices. Drivers of liking for $\mathrm{C} 2$ consumers were sweet taste, milk fat, denseness, cohesiveness, and firmness. Yogurts 112,694 , and 517 were the top choices for C2 consumers and they had the highest amounts of milk fat flavor, sweet taste, and firmness (Table 6, Figures 4 and 5). Drivers of liking for C3 consumers were milkfat flavor, viscosity, sour taste, dairy sour, and low surface grain.

Drivers of dislike can also be determined from PLS. Drivers of dislike for $\mathrm{C} 1$ consumers were sour taste, dairy sour, cooked, burnt/beefy, milk fat, and brothy/ potato flavors. Samples 815, 357, and 236 had a combination of these attributes present at higher intensities; thus, the liking scores for these yogurts were lower for $\mathrm{C} 1$ consumers. Drivers of dislike for C2 consumers were brothy/potato flavor, spoon grainy (surface grain on the spoon), and jiggle. Sample 729 had the highest amount of brothy/potato and jiggle, and this sample received lower liking scores from C2 consumers. Drivers of dislike for C3 consumers were sweet taste and burnt/ beefy and soapy flavors. Samples 015 and 112 had the lowest scores for C3 consumers, as both had high scores for sweet taste and relatively higher scores for burnt/ beefy and soapy flavors. Sample 015 also received lower liking scores from all 3 clusters.

\section{CONCLUSIONS}

Greek strained and fortified yogurts had small but distinct flavor and texture differences by descriptive sensory analysis. Consumers were aware of the increased protein content of Greek yogurts but generally unaware of differences between strained versus fortified Greek yogurt. Both strained Greek and fortified Greek yogurts received high overall liking scores in blinded acceptance testing. These results indicate that successful fortified Greek yogurts can be manufactured using addition of dried dairy ingredients or by traditional straining and centrifugation. External preference mapping demonstrated consumer preferences for a Greek yogurt having a moderate amount of sweet and sour taste, high milk fat flavor, and high firm and dense texture. Burnt/beefy flavor was a consistent driver of dislike across all 3 consumer clusters; this particular flavor was detected only in fortified Greek yogurts with added dried dairy ingredients, suggesting that careful selection of dried ingredients and processing parameters play an important role in manufacture of Greek style yogurts with consumer appeal.

\section{ACKNOWLEDGMENTS}

Funding provided in part by the Dairy Research Institute (Rosemont, IL). The use of trade names does

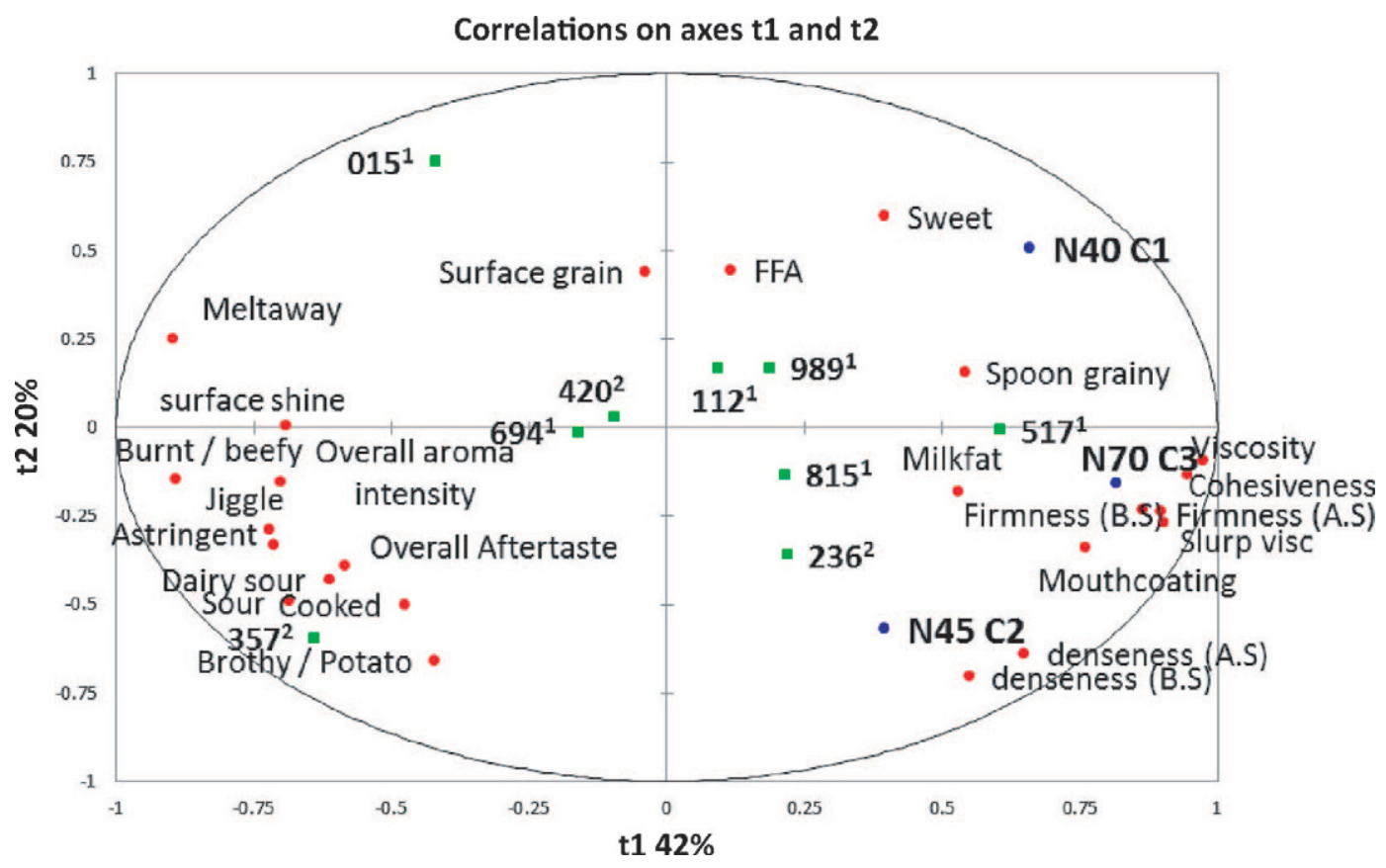

Figure 4. Partial least squares correlation biplot of clusters for Greek yogurts explaining $62 \%$ of variability. Numbers represent the Greek

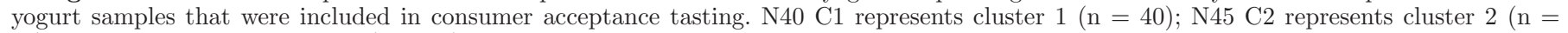

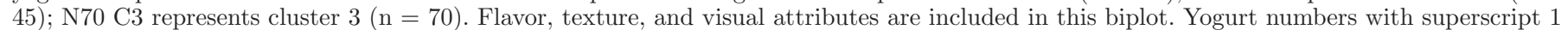

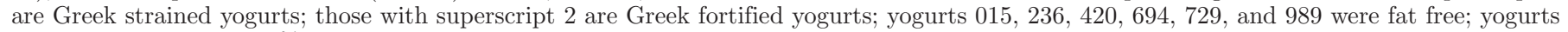

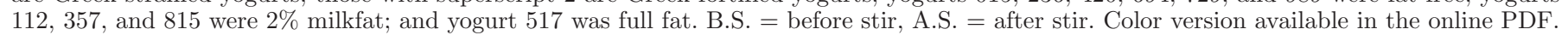


Correlations on axes $\mathrm{t} 3$ and $\mathrm{t} 4$

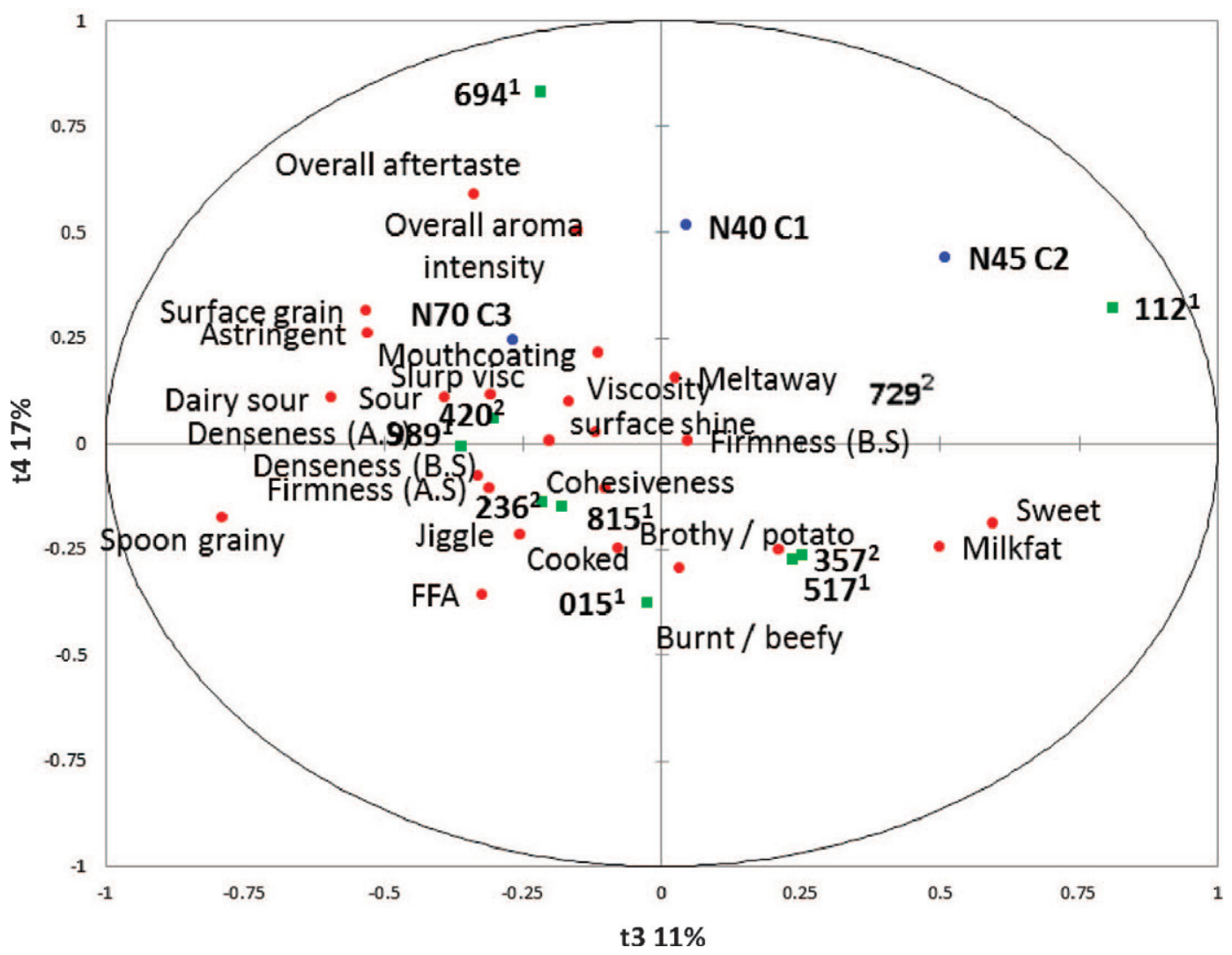

Figure 5. Partial least squares correlation biplot of clusters for Greek yogurts explaining $28 \%$ of variability. Numbers represent the Greek yogurt samples that were included in consumer acceptance tasting. N40 C1 represents cluster $1(\mathrm{n}=40)$; N45 C2 represents cluster 2 (n $=$ 45); N70 C3 represents cluster $3(\mathrm{n}=70)$. Flavor, texture and visual attributes are included in this biplot. Yogurt numbers with superscript 1 are Greek strained yogurts; those with superscript 2 are Greek fortified yogurts; yogurts 015, 236, 420, 694, 729, and 989 were fat free; yogurts 112,357 , and 815 were $2 \%$ milkfat; and yogurt 517 was full fat. B.S. = before stir, A.S. = after stir. Color version available in the online PDF

not imply endorsement or lack of endorsement of those not mentioned.

\section{REFERENCES}

Ag MRC (Agricultural Marketing Research Service). 2013. Dairy Products Profile. Accessed Oct. 11, 2013. http://www.agmrc.org/ commodities__products/livestock/dairy/dairy_products.cfm.

Allgeyer, L. C., M. J. Miller, and S. Y. Lee. 2010. Drivers of liking for yogurt drinks with prebiotics and probiotics. J. Food Sci. 75:S212-219.

AOAC International. 2012. Official Methods of Analysis. 19th ed. AOAC International, Gaithersburg, MD.

Ayub, M. 2004. Influence of different types of milk and stabilizers on sensory evaluation and whey separation of yoghurt. Pak. J. Sci. Ind. Res. 47:398-402.

Barnes, D. L., S. J. Harper, F. W. Bodyfelt, and M. R. McDaniel. 1991. Prediction of consumer acceptability of yogurt by sensory and analytical measures of sweetness and sourness. J. Dairy Sci. 74:3746-3754.

Brennan, E. M., C. Setser, and K. A. Schmidt. 2002. Yogurt thickness: Effects on flavor perception and liking. J. Food Sci. 67:2785-2788.

Codex Alimentarius. 2003. Codex Standard for Fermented Milks. Accessed Oct. 11, 2013. http://www.codexalimentarius.net/download/standards/400/CXS_243e.pdf.
Coggins, P. C., M. W. Schilling, S. Kumari, and P. D. Gerard. 2008. Development of a sensory lexicon for conventional milk yogurt in the United States. J. Sens. Stud. 23:671-687.

Dairy Foods Magazine. 2012. Nonfat Greek yogurt from Sophie. Dairy Foods Jan. 12, 2012.

Decourcelle, N., S. Lubbers, N. Vallet, P. Rondeau, and E. Guichard. 2004. Effect of thickeners and sweeteners on the release of blended aroma compounds in fat free stirred yoghurt during shear conditions. Int. Dairy J. 14:783-789.

Drake, M. A., and G. V. Civille. 2003. Flavor lexicons. Comp. Rev. Food Sci. Food Safety 2:33-40.

Drake, M. A., and M. D. Yates. 2006. Textural properties of Gouda cheese. J. Sens. Stud. 22:493-506.

Drake, S. L., P. D. Gerard, and M. A. Drake. 2008. Consumer preferences for mild Cheddar cheese flavors. J. Food Sci. 73:S449-455.

Drake, S. L., K. Lopetcharat, S. Clark, H. S. Kwak, S. Y. Lee, and M. A. Drake. 2009a. Mapping difference in consumer perception of sharp Cheddar cheese in the United States. J. Food Sci. 74:S276285.

Drake, S. L., K. Lopetcharat, and M. A. Drake. 2009b. Comparison of two methods to explore consumer preferences for cottage cheese. J. Dairy Sci. 92:5883-5897.

Foegeding, E. A., and M. A. Drake. 2007. Sensory and mechanical properties of cheese texture. J. Dairy Sci. 90:1611-1624.

Harper, S. J., D. L. Barnes, F. W. Bodyfelt, and M. R. McDaniel. 1991. Sensory ratings of commercial plain yogurts by consumer and descriptive panels. J. Dairy Sci. 74:2927-2935. 
Jaoude, D. A., A. Olabi, E. N. Najm, A. Malek, C. Saadeh, E. Baydoun, and I. Toufeili. 2010. Chemical composition, mineral content and cholesterol levels of some regular and reduced-fat white brined cheeses and strained yogurt (Labneh). Dairy Sci. Technol. 90:699-706.

Martin, N. C., J. Skokanova, E. Latrille, C. Beal, and G. Corrieu. 1999. Influence of fermentation and storage conditions on the sensory properties of plain low fat stirred yogurts. J. Sens. Stud. 14:139-160.

Meilgaard, M. M., G. V. Civille, and B. T. Carr. 2007. The Spectrum descriptive analysis method. Pages 189-254 in Sensory Evaluation Techniques. 4th ed. CRC Press, Boca Raton, FL.

Muir, D. D., and E. A. Hunter. 1992. Sensory evaluation of fermented milks; vocabulary development and the relations between sensory properties and composition between acceptability and sensory properties. J. Soc. Dairy Technol. 45:73-80.

Nsabimana, C., B. Jiang, and R. Kossah. 2005. Manufacturing, properties and shelf life of Labneh: A review. Int. J. Dairy Technol. 58:129-137.

Plemmons, L. E., and A. V. A. Resurreccion. 1999. Note on computerized data collection in consumer sensory evaluation. J. Sens. Stud. 14:19-34

Sodini, I., and P. S. Tong. 2006. Milk and milk-based dairy ingredients. Pages 167-178 in Manufacturing Yogurt and Fermented Milks. R. C. Chandan, C. H. White, A. Kilara, and Y. H. Hui, ed. Blackwell Publishing, Ames, IA.
Swaney-Stueve, M., and H. Heymann. 2002. A comparison between paper and computerized ballots and a study of simulated substitution between the two ballots used in descriptive analysis. J. Sens. Stud. 17:527-537.

Tamime, A. Y., and R. K. Robinson. 1999. Historical background. Pages 1-10 in Yogurt Science and Technology. 2nd ed. Woodhead Publ., Cambridge, UK/CRC Press, Boca Raton, FL.

Thompson, J. L., K. Lopetcharat, and M. A. Drake. 2007. Preferences for commercial strawberry drinkable yogurts among African American, Caucasian, and Hispanic consumers in the United States. J. Dairy Sci. 90:4974-4987.

US Food and Drug Administration. 2008. 21CFR131.200: Yogurt. Accessed Sep. 9, 2011. http://www.accessdata.fda.gov/scripts/cdrh/ cfdocs/cfcfr/CFRSearch.cfm?fr $=131.200$.

White, S. S., K. M. Fox, S. M. Jervis, and M. A. Drake. 2013. Influence of heating and acidification on the flavor of whey protein isolate. J. Dairy Sci. 96:1366-1379.

Whitson, M. E., R. E. Miracle, and M. A. Drake. 2010. Sensory characterization of chemical components responsible for cardboard flavor in whey protein. J. Dairy Sci. 25:616-636.

Wright, B. J., S. E. Zevchak, J. M. Wright, and M. A. Drake. 2009. The impact of agglomeration and storage on flavor and flavor stability of whey protein concentrate 80 and whey protein isolate. J Food Sci. 74:S17-S29. 